\title{
Photoluminescence of synthetic titanite-group pigments: A rare quenching effect
}

ARTICLE in CHEMIE DER ERDE - GEOCHEMISTRY • OCTOBER 2014

Impact Factor: 1.4 · DOI: 10.1016/j.chemer.2014.04.004

DOWNLOADS

59
VIEWS

78

8 AUTHORS, INCLUDING:

Teodora Stoyanova Lyubenova

Universitat Jaume I

27 PUBLICATIONS 50 CITATIONS

SEE PROFILE

Dominik Talla

University of Vienna

13 PUBLICATIONS 16 CITATIONS

SEE PROFILE
Michael Gaft

Laser Distance Spectrometry, Israel

84 PUBLICATIONS $\mathbf{1 , 0 7 9}$ CITATIONS

SEE PROFILE 


\title{
Photoluminescence of synthetic titanite-group pigments: A rare quenching effect
}

\author{
Lutz Nasdala $^{\mathrm{a}, *}$, Teodora Stoyanova Lyubenova ${ }^{\mathrm{b}}$, Michael Gaft ${ }^{\mathrm{c}}$, Manfred Wildner ${ }^{\mathrm{a}}$, \\ Wilfredo Diegor ${ }^{\mathrm{d}}$, Christian Petautschnig $^{\mathrm{a}}$, Dominik Talla ${ }^{\mathrm{e}}$, Christoph Lenz $^{\mathrm{a}}$ \\ a Institut für Mineralogie und Kristallographie, Universität Wien, Althanstr. 14, A-1090 Wien, Austria \\ b Departament de Química Inorgànica i Orgànica, University Jaume I, 12071 Castellón de la Plana, Spain \\ c OLDS Laser Distance Spectrometry Ltd., Petah-Tikva 49528, Israel \\ d Department of Earth Sciences, Memorial University of Newfoundland, St. John's, NL A1B 3X5, Canada \\ e Institute of Geological Sciences, Masaryk University, 61137 Brno, Czech Republic
}

\section{A R T I C L E I N F O}

\section{Article history:}

Received 21 October 2013

Accepted 13 April 2014

Editorial handling - Dr. K. Heide

\section{Keywords:}

Photoluminescence

Quenching

Rare-earth elements

Chromium

Titanite

\begin{abstract}
A B S T R A C T
Chromium-doped titanite and malayaite samples, which were synthesised to evaluate their performance as ceramic pigments, show remarkable photoluminescence behaviour. Emissions of centres related to traces of trivalent rare-earth elements (REE) are observed exclusively from chromium-free samples. Their Cr-doped analogues (containing the same REEs on the same concentration levels), in contrast, only show broad-band $\mathrm{Cr}^{3+}$ emission whereas all REE emissions are suppressed. This behaviour is assigned to quenching of REE emissions by chromium centres (i.e., $\mathrm{REE}^{3+} \rightarrow \mathrm{Cr}^{3+}$ energy transfer).
\end{abstract}

(c) 2014 Published by Elsevier GmbH.

\section{Introduction}

Minerals of the titanite group (general formula $\mathrm{CaX}\left[\mathrm{O} / \mathrm{SiO}_{4}\right]$, with $\mathrm{X}=\mathrm{Ti}$, Sn, $\mathrm{V}$; space group $C 2 / c$ ) have been studied extensively. Whilst titanite (CaTi[O/SiO 4 ]; Speer and Gibbs, 1976) is an ubiquitous accessory component in many igneous and metamorphic rocks, the tin silicate malayaite $\left(\mathrm{CaSn}\left[\mathrm{O} / \mathrm{SiO}_{4}\right]\right.$; Alexander and Flinter, 1965) occurs less commonly, typically in skarns (Higgins and Ribbe, 1977). The third group-member known to date is the rare mineral vanadomalayaite (Basso et al., 1994). Takenouchi (1971) has shown that at high temperatures there exists a complete solid solution between titanite and malayaite. Both of the two minerals are characterised by an excellent thermal stability and chemical resistance. For these reasons, and stimulated by their ability to incorporate a wide range of non-formula elements in their crystal lattices, synthetic analogues of titanite-group minerals have been proposed as potential host materials for the immobilisation of radioactive waste from nuclear power stations (Lutze and Ewing, 1988).

Both titanite and malayaite are colourless if chemically pure, however they become coloured when being doped with transition

\footnotetext{
* Corresponding author. Tel.: +43 1427753220 .

E-mail address: lutz.nasdala@univie.ac.at (L. Nasdala).
}

metal ions, which then act as chromophores. Especially Cr-doped malayaite, due to its intense colouration, is used commonly as a pink ceramic pigment. Correspondingly, there are many papers addressing in detail the absorption of chromium and other chromophores in titanite-group minerals, and the use of these phases as thermally stable pigments (e.g., Stefani et al., 1997; Bartis et al., 2007; Hajjaji et al., 2010; Borcanescu et al., 2013). The luminescence of titanite-group minerals, in contrast, has been investigated in very few studies only, even though "titanite may be a very interesting luminescent material" (Gaft et al., 2005). Undoped titanite shows weak green luminescence (broad band with maximum at $520 \mathrm{~nm}$ wavelength) under ultraviolet (UV) excitation, which is assigned to the "intrinsic" emission of $\mathrm{TiO}_{6}$ polyhedrons (Blasse et al., 1988). A similar, $\mathrm{Ti}^{4+}$-related broad-band emission was observed from synthetic, Ti-activated malayaite ( $\mathrm{CaSn}_{0.97} \mathrm{Ti}_{0.03} \mathrm{SiO}_{5}$; Abe et al., 2010). The emission of natural titanite, in contrast, may in some cases be most complex, comprising numerous narrow and broad bands assigned to rare-earth elements (REE, including $\mathrm{Sm}^{3+}, \mathrm{Eu}^{3+}, \mathrm{Pr}^{3+}$, $\mathrm{Nd}^{3+}, \mathrm{Tm}^{3+}, \mathrm{Er}^{3+}$ ) and transition metals (especially $\mathrm{Cr}^{3+}$; Gaft et al., 2003; Kennedy et al., 2010).

During a recent research project addressing oxidation states and lattice sites of chromophore ions in such titanite-group pigments, which was conducted at University Jaume I, Castellón de la Plana, Spain, several suites of titanite and malayaite samples with different levels of $\mathrm{Cr}$-doping were produced and characterised 
in detail (see Stoyanova Lyubenova et al., 2008, 2009a,b; Cruciani et al., 2009). In the course of a systematic spectroscopy study of these pigments that involved optical absorption, vibrational, and emission spectroscopy, we made the puzzling observation that only $\mathrm{Cr}$-free samples always show emissions of minute levels of pollutant REEs. In Cr-doped samples, by contrast, REE emissions are virtually absent. In the present study we have studied the apparently unusual behaviour for REE centres in titanite-group minerals.

\section{Samples and experimental}

\subsection{Synthesis and preparation of samples}

The Cr-doped titanite and malayaite pigments and their undoped analogues were prepared by traditional ceramic method (i.e., solid-state reaction of oxide precursors). The raw materials were mixed and homogenised with water by stirring. The powders were then dried $\left(100 \pm 5^{\circ} \mathrm{C}\right)$ and further calcined at 1200,1300 and $1400^{\circ} \mathrm{C}$ (heating rate of $3^{\circ} / \mathrm{min}$, and $4 \mathrm{~h}$ soaking time) in mullite crucibles. More details are described elsewhere (Stoyanova Lyubenova et al., 2009a,b); for generalities of the ceramics-type synthesis technique see Cordoncillo et al. (1998).

To eliminate the hypothetical possibility that the observed emission behaviour of trace REEs is an artefact caused by peculiarities of the ceramic-type pigment-synthesis process, additional flux syntheses of titanite samples (doped with $\mathrm{Nd}$, and with and without $\mathrm{Cr}$ ) were done. These samples were grown in a sodium-tetraborate flux (duration 10 days, peak temperature $1130^{\circ} \mathrm{C}$ ). The experiments corresponded mainly to the procedure described by Mazdab (2009); however we used a starting material with 1:1 molar ratio of $\mathrm{CaO}$ and $\mathrm{TiO}_{2}$ (with excess of $\mathrm{SiO}_{2}$ ). To extract titanite from the crucible, remnants of the flux were dissolved using $\mathrm{HNO}_{3}$ (30 wt\%).

For X-ray fluorescence (XRF) analysis, pigment samples were ground in a tungsten carbide mill for $2 \times 30 \mathrm{~s}$, to produce fine powders. The sample material was mixed with wax as a binder $(1: 10)$ and then pressed (with $150 \mathrm{kN}$ for $10 \mathrm{~s}$ ) in an aluminium cup on a layer of boric acid as stabilising substrate. For laser ablation inductively coupled plasma mass spectrometry (LA-ICP-MS) analysis, pigment samples were finely powered and homogenised with a pestle in a mortar under ethanol. After drying, the samples were mixed up with "White neutral pH adhesive" (Lineco, University Products, Inc.). After mixing, the samples were dried in air for several hours, cut into squares (ca. $5 \mathrm{~mm} \times 5 \mathrm{~mm}$ ) and then mounted on double-sided tape. The adhesive used is extremely pure and introduces essentially no chemical impurities to the LA-ICP-MS measurements. The only impurity elements that were detected in concentrations greater than $1 \mu \mathrm{g} / \mathrm{g}$ were $\mathrm{Si}(10 \mu \mathrm{g} / \mathrm{g})$, $\mathrm{P}(2 \mu \mathrm{g} / \mathrm{g})$, and $\mathrm{Ca}(37 \mu \mathrm{g} / \mathrm{g})$ from an average of 10 analyses of the adhesive. For back-scattered electrons imaging, samples were embedded in araldite epoxy and ground and polished; these sample mounts were also used for Raman spectroscopy. Unprepared samples were used for optical absorption and emission spectroscopy.

\subsection{Analytical techniques}

The major-element composition of pigment samples was determined, rather semi-quantitatively, by XRF analysis and X-ray diffraction (XRD) refinement. The XRF analyses were done by means of a Bruker S4 Pioneer dispersive XRF spectrometer operated at $60 \mathrm{kV}$ and $66 \mathrm{~mA}$. A LiF analyser and the standardless MultiRes programme were used. For XRD details, the reader is referred to Cruciani et al. (2009) and Stoyanova Lyubenova et al. (2009a).
The low levels of trace-REEs in the pigments were measured by LA-ICP-MS analysis. A Finnigan Element XR, high resolution double focusing magnetic sector ICP-MS, coupled to a GeoLas $193 \mathrm{~nm}$ Excimer laser system, was used. The ablated material was transported to the ICP-MS using He gas with a flow rate of $1.25 \mathrm{l} / \mathrm{min}$, with additional argon make-up gas added after the ablation cell. Laser spot sizes of $40 \mu \mathrm{m}$ (reference materials) and $59 \mu \mathrm{m}$ (ceramics) were used. The energy density was ca. $5 \mathrm{~J} / \mathrm{cm}^{2}$ with a laser repetition rate of $8 \mathrm{~s}^{-1}$. Time resolved intensity data were acquired by peak-jumping in a combination of pulse-counting and analogue modes, depending on signal strength, with one point measured per peak. The average values for $\mathrm{CaO}$ determined by the XRF analyses were used as an internal standard to normalise counts to concentrations. Elements in high abundance were analysed in analogue mode, whereas true trace elements were analysed using digital pulse counting mode. For external independent reference materials, NIST 610 and NIST 612 glasses (Pearce et al., 1997) and USGS standard BCR-2G (Jochum et al., 2005) were used for calibration. Data were reduced using the Iolite software package (Paton et al., 2011). For more experimental details on the LA-ICP-MS trace-element analysis routine at the Department of Earth Sciences, Memorial University of Newfoundland, the reader is referred to Dorais and Tubrett (2008) and Rodríguez et al. (2011).

Diffuse reflectance spectra of the titanite pigment samples were measured at room temperature in the spectral range $26,000-6000 \mathrm{~cm}^{-1}$ on a Bruker IFS66v/S Fourier-transform infrared (FTIR) spectrometer using a Perkin-Elmer diffuse reflectance accessory unit. A tungsten light source, a quartz beam-splitter, and silicon $\left(26,000-10,000 \mathrm{~cm}^{-1}\right)$ and germanium detectors $\left(10,000-6000 \mathrm{~cm}^{-1}\right)$, respectively, were used to cover the desired spectral range. Standard spectra were obtained from MgO powder. Standard and sample spectra were each averaged from 512 scans. The spectral resolution was $10 \mathrm{~cm}^{-1}$ for both detector setups. Sub-spectra were aligned in absorbance for perfect match, if necessary.

Steady-state photoluminescence (PL) spectra in the visible and near-infrared range (i.e., spectral range $21,000-10,600 \mathrm{~cm}^{-1}$ ) were obtained by means of two dispersive spectrometer systems. First, spectra with $488 \mathrm{~nm} \mathrm{Ar}^{+}$excitation ( $8 \mathrm{~mW}$ at the sample surface) were recorded using a Renishaw RM1000 system equipped with Leica DMLM microscope and a diffraction grating with 1200 grooves/mm in the optical pathway. Second, a Horiba Jobin Yvon LabRam-HR spectrometer with Olympus BX41 optical microscope and a diffraction grating with 1800 grooves $/ \mathrm{mm}$, was used to record PL spectra excited with the $473 \mathrm{~nm}$ emission of a diode laser $(3 \mathrm{~mW})$. Both systems were equipped with Si-based, Peltier-cooled charge-coupled device $(C C D)$ detector. A $50 \times$ objective $(N A=0.55)$ was used in both cases. Spectra were calibrated using emission lines of a neon lamp. The wavenumber accuracy was better than $0.5 \mathrm{~cm}^{-1}$, and the spectral resolution was determined at $\sim 3-4 \mathrm{~cm}^{-1}$ (RM1000) and better than $1 \mathrm{~cm}^{-1}$ (LabRam-HR), respectively. The latter system was used also to obtain Raman spectra for phase identification.

Time-resolved PL spectra were obtained with pulsed laser excitation (second harmonic of a Nd:YAG laser at $532 \mathrm{~nm}$ wavelength; pulse durations 5-10 ns). Spectra were obtained in $90^{\circ}$ geometry, by means of an intensified Andor iStar CCD detector synchronised to the laser pulses. The setup used enabled us to perform measurements in selectable "time windows" that are determined by the delay time $D$ (time period between the end of the laser pulse and the beginning of the measurement) and the gate width $G$ (duration between beginning and end of the measurement). With a diffraction grating with 600 grooves $/ \mathrm{mm}$ in the beam path, the spectral resolution was on the order of $8-10 \mathrm{~cm}^{-1}$ (or ca. $0.4 \mathrm{~nm}$ wavelength) in the red range. 

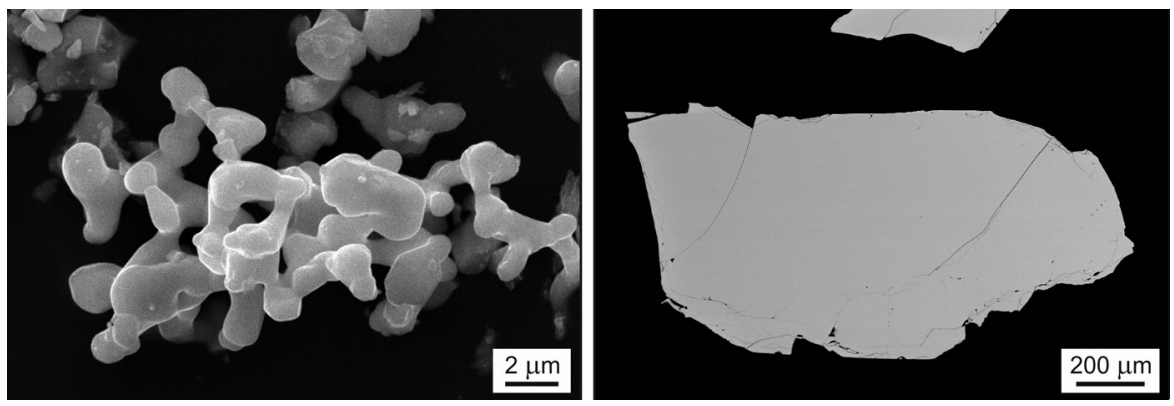

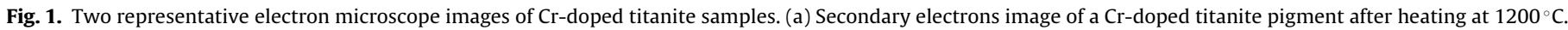
(b) Back-scattered electrons image of a polished $\mathrm{Cr}$ - and $\mathrm{Nd}$-doped titanite grown by flux synthesis.

\section{Results and discussion}

\subsection{Generalities and optical absorption}

The titanite and malayaite pigment samples are fine-grained, with crystal sizes on the order of a few micrometres (Fig. 1a). Additional titanite references that were grown by the flux technique are larger, up to one millimetre in size (Fig. 1b). All samples were found to be remarkably homogeneous, that is, no growth zoning or other internal texture was observed in back-scattered electrons images (Fig. 1b).

Titanite and malayaite samples, respectively, were cleaned mechanically by hand-picking under a powerful binocular microscope, and phase identity was then confirmed by XRD and Raman spectroscopy. In all cases, only X-ray diffraction lines and Raman bands of titanite or malayaite were found, without any indication for the presence of additional phases. Depending on their chemical compositions, colours of titanite samples vary between nearly colourless ( $\mathrm{Cr}$-free), light ochre (low-Cr), and dark ochre- to reddish-brown (high-Cr). Macroscopic colours of malayaite samples depend similarly strongly on the $\mathrm{Cr}$ content, ranging from nearly colourless to light grey ( $\mathrm{Cr}$-free) and pale pinkish (low-Cr) to intense pink (high-Cr), respectively.

Chemical compositions of the pigment samples are listed in Table 1 . Values quoted for the major oxides $\left(\mathrm{SiO}_{2}, \mathrm{CaO}, \mathrm{TiO}_{2}\right.$, $\mathrm{SnO}_{2}$ ) are means of XRF and XRD results (note that XRD results for two samples have already been published by Cruciani et al., 2009; Stoyanova Lyubenova et al., 2009a). The $\mathrm{CrO}_{2}$ concentrations quoted are means including our LA-ICP-MS results also. Chemical formulae of the three titanite pigments can be simplified to $\mathrm{CaTiSiO}_{5}, \mathrm{Ca}\left(\mathrm{Ti}_{0.98} \mathrm{Cr}_{0.02}\right) \mathrm{SiO}_{5}$, and $\mathrm{Ca}\left(\mathrm{Ti}_{0.80} \mathrm{Cr}_{0.20}\right) \mathrm{SiO}_{5}$. Analogously, simplified formulae of the three malayaite pigments are $\mathrm{Ca}\left(\mathrm{Sn}_{1.00-x} \mathrm{Cr}_{x}\right) \mathrm{SiO}_{5}(x=0, x=0.02$, and $x=0.20)$. The $\mathrm{Cr}$ per formula unit (for instance " $\mathrm{Cr}_{0.02}$ ") is used to label the samples in Table 1 and the figures.

Representative optical absorption spectra (as obtained by diffuse reflectance spectroscopy) of $\mathrm{Cr}$-free and $\mathrm{Cr}$-doped titanite pigments are shown in Fig. 2. While the $\mathrm{Cr}$-free sample lacks any significant absorption features in the visible and near-infrared (NIR) spectral ranges, the $\mathrm{Cr}$-doped samples are characterised by steadily increasing absorbance in the visible range towards the ultraviolet (UV). The absorption pattern consists of several broad bands, located roughly around $20,000,17,500$, and $13,100 \mathrm{~cm}^{-1}$, and further absorption bands in the NIR at around 10,700 and $8800 \mathrm{~cm}^{-1}$. The latter is not visible in Fig. 2 but has been reported by Stoyanova Lyubenova et al. (2008; see Fig. 7 in that paper). The resulting absorption minimum lies in the NIR at $\sim 12,000 \mathrm{~cm}^{-1}$ (Fig. 2). In the visible range, the $\mathrm{Cr}$-doping has resulted in a general increase in absorbance by a factor of 5-6.

These absorption features, resulting in brown colouration of the calcinated $\mathrm{Cr}$-doped titanite powders, have been attributed by
Table 1

Chemical compositions as determined by XRF/XRD and LA-ICP-MS (normed to 100\% total).

\begin{tabular}{|c|c|c|c|c|c|c|}
\hline \multirow[t]{2}{*}{ Constituent (unit) } & \multicolumn{3}{|c|}{ Malayaite samples } & \multicolumn{3}{|c|}{ Titanite samples } \\
\hline & Cr-free & $\mathrm{Cr}_{0.02}$ & $\mathrm{Cr}_{0.20}$ & Cr-free & $\mathrm{Cr}_{0.02}$ & $\mathrm{Cr}_{0.20}$ \\
\hline MgO (wt\%) & 0.13 & 0.10 & 0.11 & 0.10 & 0.10 & 0.19 \\
\hline $\mathrm{Al}_{2} \mathrm{O}_{3}(\mathrm{wt} \%)$ & 0.30 & 0.18 & 0.09 & 0.30 & 0.46 & 0.27 \\
\hline $\mathrm{SiO}_{2}(\mathrm{wt} \%)$ & 22.5 & 22.7 & 23.4 & 30.5 & 30.4 & 30.1 \\
\hline $\mathrm{P}_{2} \mathrm{O}_{5}(\mathrm{wt} \%)$ & (bdl) & 0.17 & 0.17 & 0.26 & 0.28 & 0.89 \\
\hline $\mathrm{SO}_{3}(\mathrm{wt} \%)$ & 0.28 & (bdl) & (bdl) & (bdl) & (bdl) & 0.09 \\
\hline $\mathrm{K}_{2} \mathrm{O}(\mathrm{wt} \%)$ & (bdl) & (bdl) & (bdl) & 0.05 & 0.04 & 0.05 \\
\hline $\mathrm{CaO}(\mathrm{wt} \%)$ & 20.9 & 20.7 & 21.7 & 28.6 & 27.9 & 28.3 \\
\hline $\mathrm{TiO}_{2}(\mathrm{wt} \%)$ & (bdl) & (bdl) & 0.26 & 40.0 & 39.6 & 30.0 \\
\hline $\mathrm{CrO}_{2}(\mathrm{wt} \%)^{\mathrm{a}}$ & (bdl) & 0.85 & 8.30 & (bdl) & 0.91 & 9.88 \\
\hline $\mathrm{Fe}_{2} \mathrm{O}_{3}(\mathrm{wt} \%)$ & 0.51 & 0.08 & 0.11 & 0.07 & 0.12 & 0.20 \\
\hline $\mathrm{ZnO}(\mathrm{wt} \%)$ & (bdl) & (bdl) & (bdl) & (bdl) & 0.09 & (bdl) \\
\hline $\mathrm{SrO}(\mathrm{wt} \%)$ & 0.05 & 0.04 & (bdl) & (bdl) & (bdl) & (bdl) \\
\hline $\mathrm{ZrO}_{2}(\mathrm{wt} \%)$ & (bdl) & 0.04 & (bdl) & (bdl) & (bdl) & (bdl) \\
\hline $\mathrm{SnO}_{2}(\mathrm{wt} \%)$ & 55.3 & 55.1 & 45.9 & (bdl) & (bdl) & (bdl) \\
\hline $\mathrm{WO}_{3}(\mathrm{wt} \%)^{\mathrm{b}}$ & (bdl) & (bdl) & (bdl) & 0.06 & 0.02 & (bdl) \\
\hline $\operatorname{Pr}(\mu \mathrm{g} / \mathrm{g})$ & 0.6 & 0.5 & 0.3 & 0.9 & 0.9 & 0.7 \\
\hline $\mathrm{Nd}(\mu \mathrm{g} / \mathrm{g})$ & 18.8 & 13.9 & 7.4 & 5.7 & 8.6 & 4.1 \\
\hline $\operatorname{Sm}(\mu \mathrm{g} / \mathrm{g})$ & 0.4 & 0.5 & 0.1 & 0.8 & 0.8 & 0.5 \\
\hline $\mathrm{Eu}(\mu \mathrm{g} / \mathrm{g})$ & 0.1 & 0.1 & 0.5 & 0.1 & 0.4 & 0.2 \\
\hline $\operatorname{Er}(\mu \mathrm{g} / \mathrm{g})$ & 0.2 & 0.3 & 0.2 & 0.4 & 0.4 & 0.2 \\
\hline
\end{tabular}

bdl: Not detected, or results below the $3 \sigma$ detection limit.

a Chromium is quoted as $\mathrm{CrO}_{2}$ because in the samples studied, chromium is predominantly present as $\mathrm{Cr}^{4+}$, replacing $\mathrm{Sn}^{4+}$ (cf. Cruciani et al., 2009) or $\mathrm{Ti}^{4+}$ (Stoyanova Lyubenova et al., 2009a,b), respectively. Values quoted are means of XRF, XRD, and LA-ICP-MS results.

b Tungsten is a contaminant resulting from the grinding process.

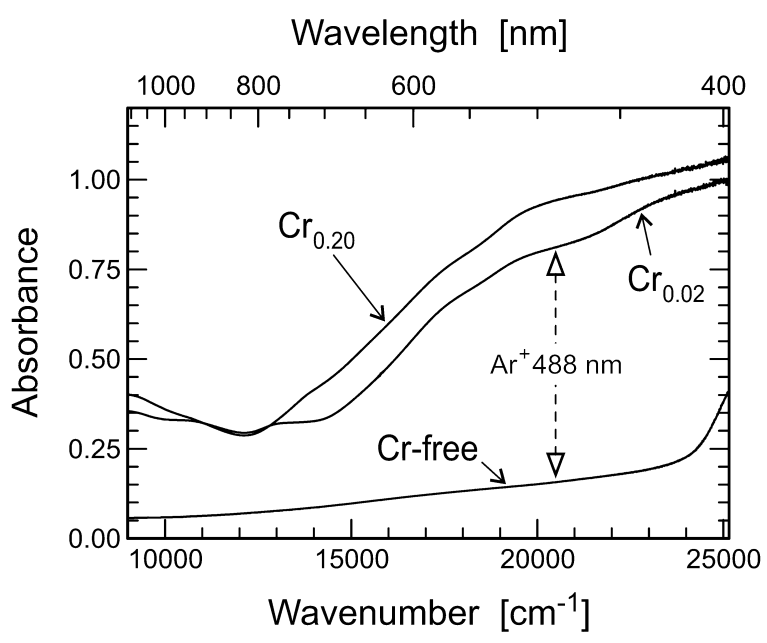

Fig. 2. Optical absorption spectra of the three titanite pigments. Note that the $\mathrm{Cr}$ doping has resulted in ca. 5-6-fold increase of the absorption of the blue laser light (see grey arrow) used to excite the PL spectra presented in Fig. 3. 
a

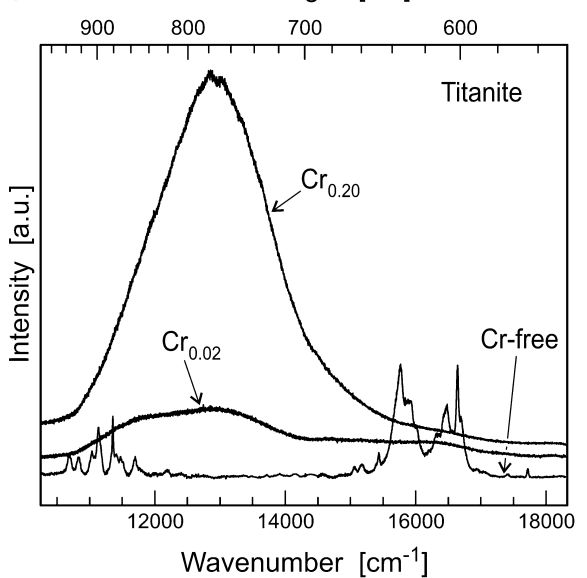

b

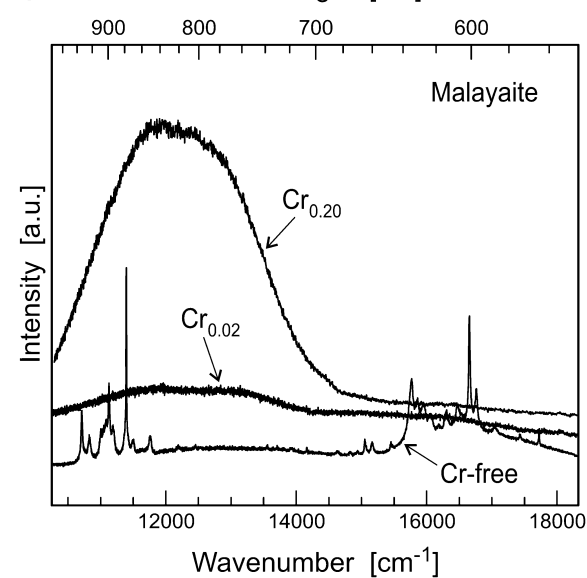

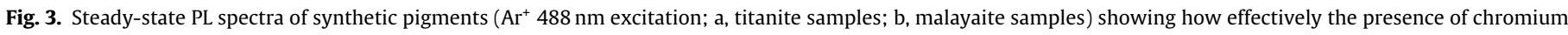
controls the appearance or absence of REE-related emissions.

Stoyanova Lyubenova et al. (2008) to co-actions of crystal-field transitions of $\mathrm{Cr}^{3+}$ ions in octahedral, and $\mathrm{Cr}^{4+}$ ions in octahedral as well as tetrahedral sites; and we adopt their interpretation to the discernible bands and shoulders in Fig. 2. However, we propose that in the visible spectral range these crystal-field bands are superposed on the low-energy wing of a UV absorption edge (or pre-edge band), probably caused by ligand-metal charge-transfer of $\mathrm{Cr}^{6+}$ cations replacing $\mathrm{Si}^{4+}$ in the tetrahedral sites of the titanite structure. It has been shown that tetrahedrally oxygen-coordinated $\mathrm{Cr}^{6+}$, even if only present in trace amounts, may cause a significant red-shift of the fundamental absorption edge or a broad chargetransfer pre-edge band (e.g. Talla et al., 2013). The widely similar ionic radii of $\mathrm{Cr}^{6+}$ and $\mathrm{Si}^{4+}$ in tetrahedral coordination (Shannon, 1976) might also facilitate a partial oxidation of $\left(\mathrm{Cr}^{4+}\right)^{[4]}$ to $\left(\mathrm{Cr}^{6+}\right)^{[4]}$ at high calcination temperatures. This hypothesis seems to be in accordance with observations of Stoyanova Lyubenova et al. (2008) who reported a colour change from yellow to brown colour for $\mathrm{Cr}$-doped titanite pigments after calcination at $\geq 1000^{\circ} \mathrm{C}$.

\subsection{Photoluminescence}

Steady-state PL spectra obtained under blue laser excitation are presented in Fig. 3. Spectra of undoped titanite and malayaite pigments do not show any significant "intrinsic" feature but, instead, groups of narrow emission bands in the orange-red to NIR region of the electromagnetic spectrum. The absence of "intrinsic" emissions corresponds to the results of Abe et al. (2010) who did not observe any emission from pure $\mathrm{CaTiSiO}_{5}$ and $\mathrm{CaSnSiO}_{5}$. The observation is also consistent with the results of Blasse et al. (1988): These authors reported that the green "intrinsic" broad-band emission of titanite is excited by mid-range UV light (excitation maximum reported at $290 \mathrm{~nm}$ wavelength) but not under long-wave UV or visible excitation. The groups of narrow emission bands are assigned to REEs, in particular $\mathrm{Pr}^{3+}$ and $\mathrm{Sm}^{3+}$ (perhaps also $\mathrm{Er}^{3+}$ ) in the orange-red, and $\mathrm{Nd}^{3+}$ (and ancillary $\mathrm{Er}^{3+}$ ) in the NIR. As pigment samples have not been doped intentionally, the origins of these REEs are assigned to minute pollutions of the starting oxides.

The REEs, whose emissions are observed in PL spectra, are interpreted as incorporated in the titanite and malayaite lattice, respectively, rather than forming separate phases. In the case of titanite samples, this interpretation is supported strongly by the fact that groups of $\mathrm{REE}^{3+}$ emission bands show fine-structures that are typical of REEs in titanite (compare spectra published by Gaft et al., 2003; Kennedy et al., 2010). In contrast, if REE-bearing phases other than titanite were present (i.e. if emitting REEs were incorporated in different solids), different crystal-field effects would result in notably different fine-structures of electronic transitions (Gaft et al., 2005; Lenz et al., 2013). To the best of our knowledge, no appropriate references for the REE-PL of malayaite have been published thus far. However, the remarkable similarity of fine-structures of REE emissions of malayaite samples compared to those of titanite samples (see Fig. 3), supports REE incorporation in the malayaite lattice (which is iso-structural with titanite).

As expected, Cr-doped samples show the typical broad-band emission of $\mathrm{Cr}^{3+}$ whose intensity seems to correlate well with the $\mathrm{Cr}$ concentration (Fig. 3). Note that only a small fraction of the chromium is present as $\mathrm{Cr}^{3+}$ whereas the majority of this element is tetravalent (Cruciani et al., 2009; Stoyanova Lyubenova et al., 2008, 2009a); nevertheless the absolute quantity of the trivalent fraction of chromium is sufficient to cause intense PL emission. The PL emission of tetrahedrally coordinated $\mathrm{Cr}^{4+}$ has been observed in synthetic apatite (Gaft and Panczer, 2013), but to the best of our knowledge not in natural minerals thus far. Even if there was $\mathrm{Cr}^{4+}$ emission from our pigment samples, it would be rather irrelevant for our PL spectra: This emission, if present, is to be expected at low quantum energies of ca. $0.9-1.0 \mathrm{eV}$ (ca. $1.3 \mu \mathrm{m}$ wavelength; Gaft et al., 2005), which is far off the sensitivity range of the Si-based CCD detectors in the spectrometers used here.

Most remarkably, the narrow REE emission lines have disappeared completely in all $\mathrm{Cr}$-doped samples. There are two hypothetically feasible reasons for this. First, the presence of chromium in the crucible could hinder the incorporation of traceREEs into titanite/malayaite lattice. The absence of REE lines in the spectra would then be due to the absence of REE centres. Second, if the REEs are not excluded during crystal growth but present in the lattice, the simultaneous presence of sufficient amounts of $\mathrm{Cr}$ could suppress REE emissions. It was therefore crucial to measure concentrations of trace-REEs in all pigment samples. Results are quoted in the lower part of Table 1. As more or less uniform REE contents were measured in all samples, the former hypothesis can be excluded, and the observed emission behaviour is assigned to quenching of $\mathrm{REE}^{3+}$ emissions by $\mathrm{Cr}^{3+}$ centres (compare Reisfeld and Jørgensen, 1977).

To verify the above quenching effect, which was first observed from mildly REE-contaminated pigment samples, a suite of additional titanite samples, intentionally doped with REEs, were grown in a sodium-borate flux. Photoluminescence spectra of two Nddoped samples are shown in Fig. 4. In the spectrum of Nd-doped $\mathrm{Cr}$-free titanite (nearly colourless sample; lower spectrum in Fig. 4) it can be seen that the starting $\mathrm{Nd}_{2} \mathrm{O}_{3}$ was somehow impure and 


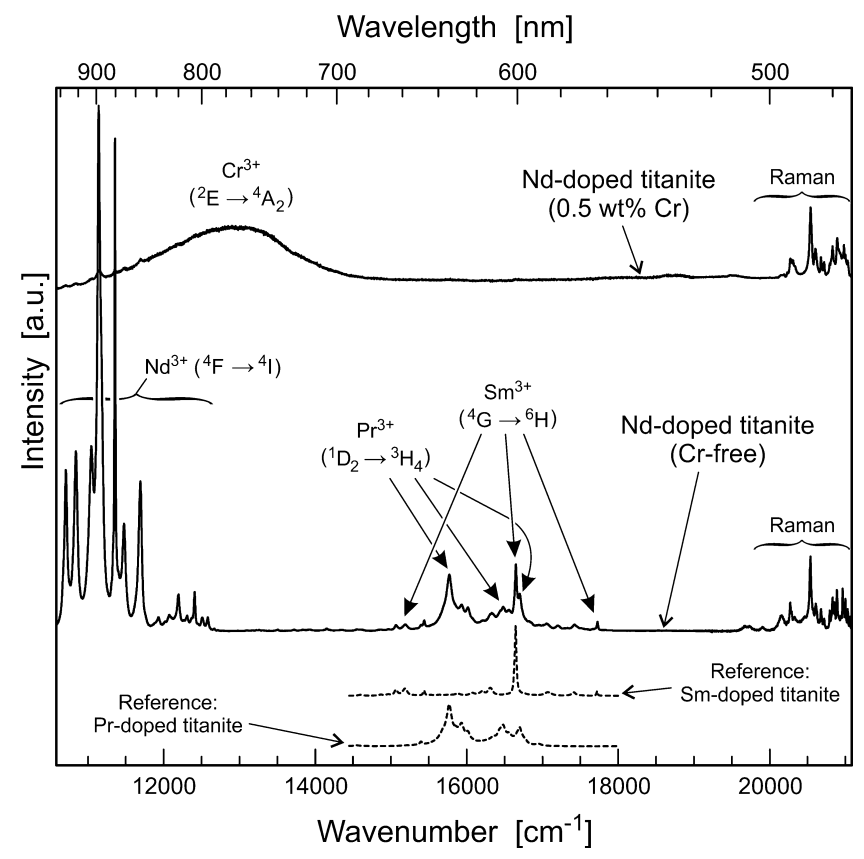

Fig. 4. Steady-state PL spectra of two flux-grown titanite samples ( $473 \mathrm{~nm}$ excitation). Dashed graph, Cr-free sample containing $520 \mu \mathrm{g} / \mathrm{g} \mathrm{Nd}$; solid graph, Cr-bearing sample containing $340 \mu \mathrm{g} / \mathrm{g}$ Nd. Spectra are shown with vertical offset for more clarity.

contained low levels of pollutant Sm and $\operatorname{Pr}$ (interpretation verified by reference spectra of Sm- and Pr-doped titanite), causing emissions in the orange to red spectral range. The fact that $\mathrm{Sm}^{3+}$ and $\mathrm{Pr}^{3+}$ emissions, in spite of their trace concentration, are relatively strong in intensity, is assigned to the particular effectiveness of the blue laser to excite these centres and the much higher sensitivity of Si-based CCDs in the visible range, compared to the NIR. This consideration is supported by the spectrum of $\mathrm{Cr}$-free titanite in Fig. 3a: The emissions of $\operatorname{Pr}$ and $\operatorname{Sm}\left(15,500-17,000 \mathrm{~cm}^{-1}\right)$ are much higher in intensity than the emission of $\mathrm{Nd}$ (below $11,500 \mathrm{~cm}^{-1}$ ), even though $\mathrm{Nd}$ is present in much higher quantity (see Table 1 ).

The upper spectrum in Fig. 4 was obtained from Nd-doped titanite containing $0.5 \mathrm{wt} \% \mathrm{Cr}$ (dark olive-brown coloured sample). It is dominated by the broad emission band of $\mathrm{Cr}^{3+}$. Emissions of REEs are either reduced considerably (the $\mathrm{Nd}^{3+}$ emission in the NIR is reduced to ca. $2 \%$ of its intensity in the $\mathrm{Cr}$-free sample, even though the concentrations are on the same order of magnitude) or extinct $\left(\mathrm{Pr}^{3+}\right.$ and $\left.\mathrm{Sm}^{3+}\right)$. This shows that, again, the presence of a sufficient amount of chromium suppresses the emission of REEs. Obviously, broad $\mathrm{Cr}^{3+}$ and narrow REE emissions are observed simultaneously (see Fig. 2 of Gaft et al., 2003, and Fig. 3B of Kennedy et al., 2010) only for samples with comparably moderate $\mathrm{Cr}$ concentration and virtual "REE excess" (compare Table 1 of Gaft et al., 2003).

A small selection of time-resolved PL spectra of titanite pigments are presented in Fig. 5. The spectrum of the undoped sample (Fig. 5a) is dominated by narrow emission lines assigned to REE centres. The decay time $(\tau)$ of the $\mathrm{Nd}^{3+}$ emission near $11,000-11,500 \mathrm{~cm}^{-1}$ (ca. $900 \mathrm{~nm}$ wavelength) was determined at $150-200 \mu \mathrm{s}$, which is about one order of magnitude longer than the typical decay time of the ${ }^{4} \mathrm{~F}_{3 / 2} \rightarrow{ }^{4} \mathrm{I}_{9 / 2} \mathrm{Nd}^{3+}$ emission in natural titanite ( $\tau \sim 10-30 \mu \mathrm{s}$; see also Gaft et al., 2003). In analogy to the steady-state PL spectra discussed above, time-resolved PL spectra of $\mathrm{Cr}$-doped titanite pigments do not show REE emissions but only the broad ${ }^{2} \mathrm{E} \rightarrow{ }^{4} \mathrm{~A}_{2}$ emission of $\mathrm{Cr}^{3+}$ (Fig. 5b,c). The spectra indicate the presence of two different types of $\mathrm{Cr}^{3+}$ emission centres, characterised by slightly different maxima and decay times. They are assigned to $\mathrm{Cr}^{3+}$ ions in positions with weaker and stronger crystal field, respectively. Variable occupation of these $\mathrm{Cr}$ sites may also explain variations in the spectral position of the $\mathrm{Cr}^{3+}$ emission band in steady-state PL spectra (compare for instance $\mathrm{Cr}_{0.02}$ and $\mathrm{Cr}_{0.20}$ in Fig. 3a).

The general disappearance of REE emission lines accompanying the incorporation of notable chromium concentrations is quite unusual, and difficult to explain. The relatively long decay time of $\mathrm{Nd}^{3+}$ points to the possibility in the $\mathrm{Cr}$-free pigments, REEs (or at least a part of the REE centres present) are not excited directly but through non-radiative energy transfer via (an)other centre(s) with relatively long decay time. In Cr-bearing pigments, in contrast, the REEs do not emit; rather, the excitation energy is preferentially transferred to trivalent chromium. This may be due partially to the enhanced absorption of the exciting laser light by chromium; however a ca. 5-6-fold increase in absorption (Fig. 2) alone is unable to cause a decrease in REE emissions by more than two orders of magnitude (Fig. 3). It appears much more likely that in $\mathrm{Cr}$-bearing samples, the $\mathrm{Cr}^{3+}$ centres present quench the $\mathrm{REE}^{3+}$ emissions, that is, energy migrates from REE centres to $\mathrm{Cr}^{3+}$ by non-radiative mechanisms. The (re)absorption of potential REE emissions by $\mathrm{Cr}^{3+}$ needs
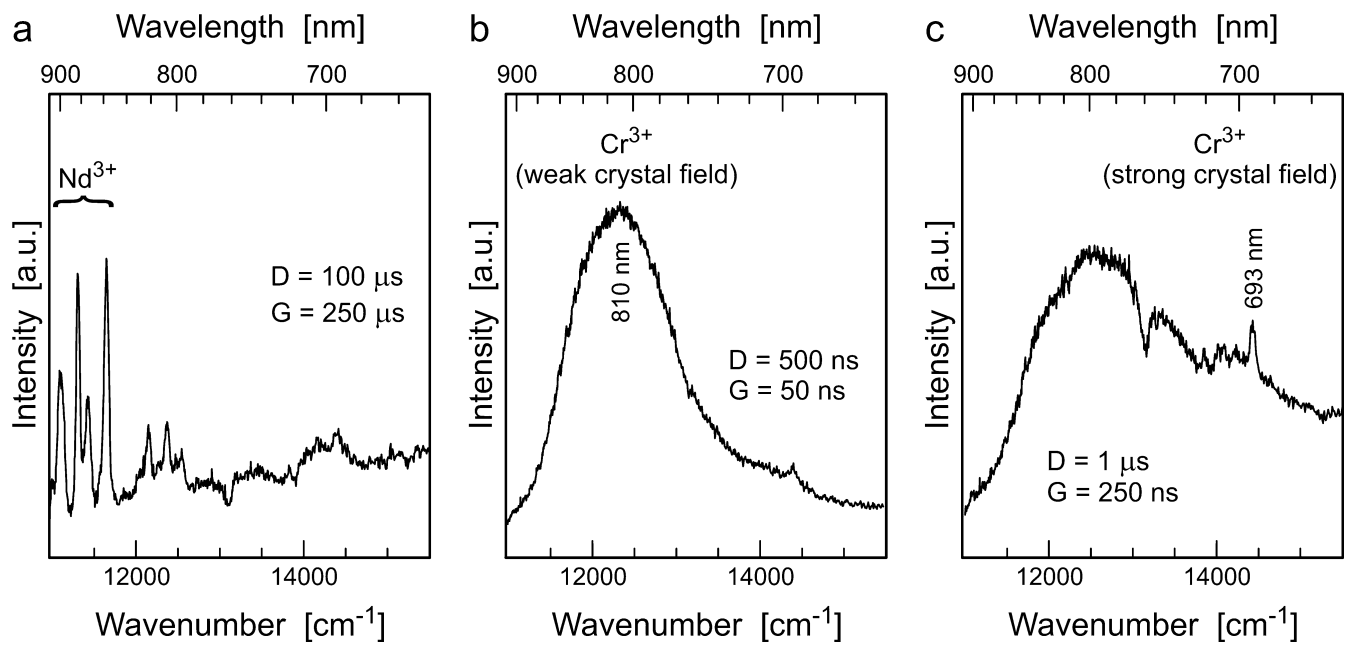

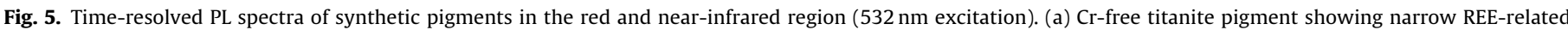

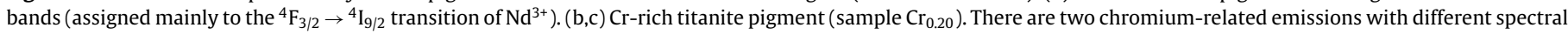
positions and decay times. 
to be considered also. Quenching of REE luminescence by trivalent chromium has already been discussed by Reisfeld and Jørgensen (1977) who presented several examples. To the best of our knowledge, $\mathrm{REE} \rightarrow \mathrm{Cr}$ energy transfer has however not been reported for titanite-structured minerals thus far.

Remarkably, this process affects REE emissions with lower (e.g., $\mathrm{Nd}^{3+}$ at $<1.4 \mathrm{eV}$ ) as well as REE emissions with higher energy (e.g., $\mathrm{Pr}^{3+}$ at $\sim 2 \mathrm{eV}$ ), compared to the ca. 1.46-1.61 eV transition of $\mathrm{Cr}^{3+}$ in titanite (see again Figs. 3 and 4). This suggests that evidently there is a - quite effective - energy migration from excited states of the REEs to an excited state of trivalent chromium.

\section{Acknowledgements}

Thanks are due to J.M. Hanchar for help with the preparation of LA-ICP-MS samples, and J. Carda and M. Tubrett for constructive comments. A part of the major-element analyses were kindly done by R. Janjic, Bruker AXS, Karlsruhe, Germany. Electron microscope images were obtained by R. Škoda. Financial support was provided by the Austrian Science Fund (FWF), grant P24448-N19 to L.N. Co-author T.S.L. acknowledges financial support by the Spanish Ministry of Science and Education in the framework of project "Formation of University Professors" (FPU).

\section{References}

Abe, S., Yamane, H., Yoshida, H., 2010. Synthesis and photoluminescence of Ca-(Sn,Ti)-Si-O compounds. Mater. Res. Bull. 45, 367-372.

Alexander, J.B., Flinter, B.H., 1965. A note on varlamoffite and associated minerals from the Batang Padang district, Perak, Malaya, Malaysia. Mineral. Mag. 35, 622-627.

Bartis, T., Lazau, R.I., Becherescu, D., Lazau, I., Pacurariu, C., Matea, O., 2007. Synthesis of some pink malayaite pigments and study of their behavior in ceramic glazes. Rev. Rom. Mater. 37, 113-121.

Basso, R., Lucchetti, G., Zefiro, L., Palenzona, A., 1994. Vanadomalayaite, CaVOSiO a new vanadium analog of titanite and malayaite. Neues Jb. Miner. Monat. 11, 489-498.

Blasse, G., Dirksen, G.J., Tanaka, I., Kojima, H., 1988. The luminescence of titanite (CaTiSiO $)$ ). Mater. Res. Bull. 23, 1727-1730

Borcanescu, S., Lazau, I., Lazau, R.I., Pacurariu, C., 2013. Malayaite pink pigments behaviour in colouring some tableware faience glazes. Rev. Rom. Mater. 43, 90-95.

Cordoncillo, E., del Rio, F., Carda, J., Llusar, M., Escribano, P., 1998. Influence of some mineralizers in the synthesis of sphene-pink pigments. J. Eur. Ceram. Soc. 18, 1115-1120.

Cruciani, G., Dondi, M., Ardit, M., Stoyanova Lyubenova, T., Carda, J.B., Matteucci, F., Costa, A.L., 2009. Malayaite ceramic pigments: a combined optical spectroscopy and neutron/X-ray diffraction study. Mater. Res. Bull. 44, 1778-1785.

Dorais, M.J., Tubrett, M., 2008. Identification of a subduction zone component in the Higganum dike, Central Atlantic Magmatic Province: A LA-ICPMS study of clinopyroxene with implications for flood basalt petrogenesis. Geochem. Geophys. Geosyst. 9, Q10005.
Gaft, M., Panczer, G., 2013. Laser-induced time-resolved luminescence spectroscopy of minerals: a powerful tool for studying the nature of emission centres. Mineral. Petrol 107, 363-372.

Gaft, M., Nagli, L., Reisfeld, R., Panczer, G., 2003. Laser-induced time-resolved luminescence of natural titanite $\mathrm{CaTiOSiO}_{4}$. Opt. Mater. 24, 231-241.

Gaft, M., Reisfeld, R., Panczer, G., 2005. Modern Luminescence Spectroscopy of Minerals and Materials. Springer, Berlin Heidelberg, New York, 356 pp.

Hajjaji, W., Zanelli, C., Seabra, M.P., Dondi, M., Labrincha, J.A., 2010. Cr-doped titanite pigment based on industrial rejects. Chem. Eng. J. 158, 167-172.

Higgins, J.B., Ribbe, P.H., 1977. The structure of malayaite, $\mathrm{CaSnOSiO}_{4}$, a tin analog of titanite. Am. Mineral. 62, 801-806.

Jochum, K.P., Nohl, U., Herwig, K., Lammel, E., Stoll, B., Hofmann, A.W., 2005. Geo ReM: a new geochemical database for reference materials and isotopic standards. Geostand. Geoanal. Res. 29, 333-338.

Kennedy, A.K., Kamo, S.L., Nasdala, L., Timms, N.E., 2010. Greenville skarn titanite: potential reference material for SIMS U-Th-Pb analysis. Can. Mineral. 48, $1423-1443$

Lenz, C., Talla, D., Ruschel, K., Škoda, R., Götze, J., Nasdala, L., 2013. Factors affecting the $\mathrm{Nd}^{3+}\left(\mathrm{REE}^{3+}\right)$ luminescence in minerals. Miner. Petrol. 107, 415-428.

Lutze, W., Ewing, R.C., 1988. Summary and evaluation of waste forms. In: Lutze, W., Ewing, R.C. (Eds.), Radioactive Waste Forms for the Future. North-Holland Physics Publishing, Amsterdam, pp. 699-740.

Mazdab, F., 2009. Characterization of flux-grown trace-element-doped titanite using the high-mass-resolution ion microprobe (SHRIMP-RG). Can. Mineral. 47, 813-831.

Paton, C., Hellstrom, J.C., Paul, B.T., Woodhead, J.D., Hergt, J.M., 2011. Iolite: Freeware for the visualisation and processing of mass spectrometric data. J. Anal. Atom. Spectrom. 26, 2508-2518.

Pearce, N.J.G., Perkins, W.T., Westgate, J.A., Gorton, M.P., Jackson, S.E., Neal, C.R., Chenery, S.P., 1997. A compilation of new and published major and trace element data for NIST SRM 610 and NIST SRM 612 glass reference materials. Geostandards Newslett. 21, 115-144.

Reisfeld, R., Jørgensen, C.K., 1977. Lasers and Excited States of Rare Earths. Springer Berlin Heidelberg, pp. 226p.

Rodríguez, H.B., Lozano, D.O., Martínez, Y.A.R., Pérez, A.G.A., Balogh, A.G., Cabri, J.L., 2011. Quantification of refractory gold in grains of pyrite and arsenopyrite from the El Diamante gold mine in Nariño-Colombia. Revista Tumbaga 6, $153-164$.

Shannon, R.D., 1976. Revised effective ionic radii and systematic studies of interatomic distances in halides and chalcogenides. Acta Cryst. A32 $751-767$.

Speer, J.A., Gibbs, G.V., 1976. The crystal structure of titanite, CaTiSiO 5 , and the domain textures of natural titanites. Am. Mineral. 61, 238-247.

Stefani, R., Longo, E., Escribano, P., Cordonciollo, E., Carda, J.B., 1997. Developing a pink pigment for glazes. Am. Ceram. Soc. Bull. 76, 61-64.

Stoyanova Lyubenova, T., Ocaña, M., Carda, J., 2008. Brown ceramic pigments based on chromium(III)-doped titanite obtained by spray pyrolysis. Dyes Pigments 79, 265-269.

Stoyanova Lyubenova, T., Matteucci, F., Costa, A.L., Dondi, M., Ocaña, M., Carda, J., 2009a. Synthesis of $\mathrm{Cr}$-doped $\mathrm{CaTiSiO}_{5}$ ceramic pigments by spray drying. Mater. Res. Bull. 44, 918-924.

Stoyanova Lyubenova, T., Matteucci, F., Costa, A.L., Dondi, M., Carda, J., 2009b. Ceramic pigments with sphene structure obtained by both spray- and freezedrying techniques. Powder Technol. 193, 1-5.

Takenouchi, S., 1971. Hydrothermal synthesis and consideration of the genesis of malayaite. Miner. Deposita 6, 335-347.

Talla, D., Wildner, M., Beran, A., Škoda, R., Losos, Z., 2013. On the presence of hydrous defects in differently coloured wulfenites $\left(\mathrm{PbMoO}_{4}\right)$ : an infrared and optical spectroscopic study. Phys. Chem. Miner. 40, 757-769. 